\title{
A Comprehensive Evaluation of Eye Surgery Performance by Sigma Quality Level for Eye Care Hospitals in Turkey
}

\author{
İbrahim Şahbaz ${ }^{1}$, Mehmet Tolga Taner², Gamze Kağan³, Engin Erbaş ${ }^{4}$ \\ ${ }^{1}$ Department of Opticianry, Üsküdar University, Istanbul, Turkey \\ ${ }^{2}$ Department of Business Administration, Doğuş University, Istanbul, Turkey \\ ${ }^{3}$ Department of Occupational Health and Safety, Üsküdar University, Istanbul, Turkey \\ ${ }^{4}$ Institute of Health Sciences, Üsküdar University, Istanbul, Turkey \\ Email: ibrahim.sahbaz@uskudar.edu.tr, mtaner@dogus.edu.tr, gamze.kagan@uskudar.edu.tr, \\ enginerbas78@hotmail.com
}

Received 15 June 2015; accepted 16 August 2015; published 19 August 2015

Copyright (C) 2015 by authors and Scientific Research Publishing Inc.

This work is licensed under the Creative Commons Attribution International License (CC BY).

http://creativecommons.org/licenses/by/4.0/

(c) (i) Open Access

\section{Abstract}

Sigma Quality Levels are statistical indices that can play an important role in establishment of more reliable and robust surgical processes. This article aims to highlight the value of interpreting sigma levels as a modern means of both the efficiency and success rate of nine different type of eye surgery processes involved. Data were compiled from a comprehensive study of multiple sources-all based on medical practices-carried out in a range of eye care hospitals throughout Turkey. It is found that the eye surgery processes in Turkey operates at an average of 3.4816 sigma level. This corresponds to a DPMO of 23,725 and a yield of approximately $97.63 \%$ in 7292 surgeries. Thus, Turkish eye care hospitals have to make significant changes to drive to a $6 \sigma$ level performance.

Keywords

Six Sigma, Ophthalmology, Surgeries, Complications

\section{Introduction}

During the past three decades, profound tecnological advances such as lasers, molecular genetics and immunology, have occurred in the diverse fields of medicine [1]. This progress has encouraged similar advances in almost every aspect of ophthalmic practice. The implementation and adaptation of so much information lead to 
more robust practices resulting in far fewer types of complication [2].

Pertaining to both ocular and visual health, maintenance and restoration are complimentary parts of the overall management of patients with eye diseases [3]. However, eye surgeries are often further complicated by results which may lead to a major cost burden on the healthcare systems and even endanger the patient's life resulting in the loss of well-being and the quality of life by undergoing the risk. This burden may include direct costs of treating these complications, opportunity costs and lost productivity costs due to disability as well as the indirect costs related to extended periof of stay in hospital. In some cases, due to ophthalmic drugs being of high costs, financial burden can also play a key role in treatment.

Each surgical procedure carries certain risks with it. Therefore, it is impossible to guarantee that it will produce perfect results without complications [2]. While most eye surgeries have become reliably safe procedures with the vast amount of surgical experience accumulated and the presence of high technology equipment, complications are an expected part of surgical practice [3]. Since these acute, sub-acute and/or chronic conditions take serious toll on human health, economic and emotional pressures at times leading to acute life-threatening complications, their elimination by continuously improved ophthalmic surgical processes is self evident.

Most surgeries are complicated processes where at least a standard outcome is desired by the independent skills but collective work of ophthalmic surgeon, nurse, assistant surgeon and technician who are also reliant on equipment and materials. Some examples for desired outcomes of ophthalmic surgeries may include ocular alignment, high visual acuity, high vision quality, corrected refractive error, emmetropia, orthophoria, fusion, clear cornea and excellent prognosis. Certain complications do not usually occur if the surgery was not performed in a manner below this standard of care. On the other hand, certain complications may be difficult for even the most experienced surgeon to protect against while others might be complications which only seldom occur due to surgeon negligence.

Eye research has grown exponentially in recent years requiring the personnel involved to maintain a consistent and updated level of knowledge and technique so as to remain abreast of all modern clinical procedures and the scientists to revise their individual fields of expertise [1]. Coupled with this dichotomy is the wide range of complications to establish their root causes and their prevention depends on many variables. These variables necessitate a reference work that provides concise, easily understandable information on a wide range of surgeries.

This study presents and compares the complication rates of nine different types of eye surgeries, namely trabulectomy, IntraLase surgery, intravitreal injections, cataract surgery in patients with pseudoexfoliation syndrome, pars plana vitrectomy, phacoemulsification cataract surgery, penetrating keratoplasty and LASIK surgery and strabismus surgery [4]-[12]. To achieve this, a Six Sigma metric named Sigma Quality Level is employed.

\section{Methodology}

In recent years, Six Sigma has become the most popular quality and process improvement methodology which strives for elimination of defects in the processes whose origin is traced back to the pioneering and innovation made at Motorola Company and its adoption by many manufacturing and service companies worldwide [13]. It is improving the outcomes of modern healthcare processes today [14].

Six Sigma Methodology is a statistical approach to measure variance incorporating normal distribution.The more standard deviations $(\sigma)$, i.e. an indicator of the variation of the process, the more capable is the process. A Six Sigma process means that $6 \sigma$ equates in percentage terms to $99.99966 \%$ accuracy or to 3.4 defects per million opportunities (DPMO) to make a defect (Figure 1).

Sigma Quality Level is a measure used to indicate how often the defects are likely to occur. It is a simple statistic that puts a given defect rate on a "six-sigma" scale and measures the quality maturity of the process. Here, sigma is a mathematical term and the key measure of variability. It emphasizes need to control both the average and variability of a process. According to [15], most companies produce a defect rate of between 35,000 and 50,000 of DPMO which equates to a sigma quality level of $3 \sigma$ to $3.5 \sigma$.

Table 1 shows different Sigma levels and associated defects per million opportunities. The statistical representation of Six Sigma describes quantitatively how a process is performing. For example, $1 \sigma$ level indicates that it tolerates 690,000 defects per million opportunities with $30.9 \%$ yield. $6 \sigma$ level allows only 3.4 defects per million opportunities with 99.99966 yield. This means that $6 \sigma$ is not the same as zero defects, however, it is a significant threshold of performance (Table 1). 


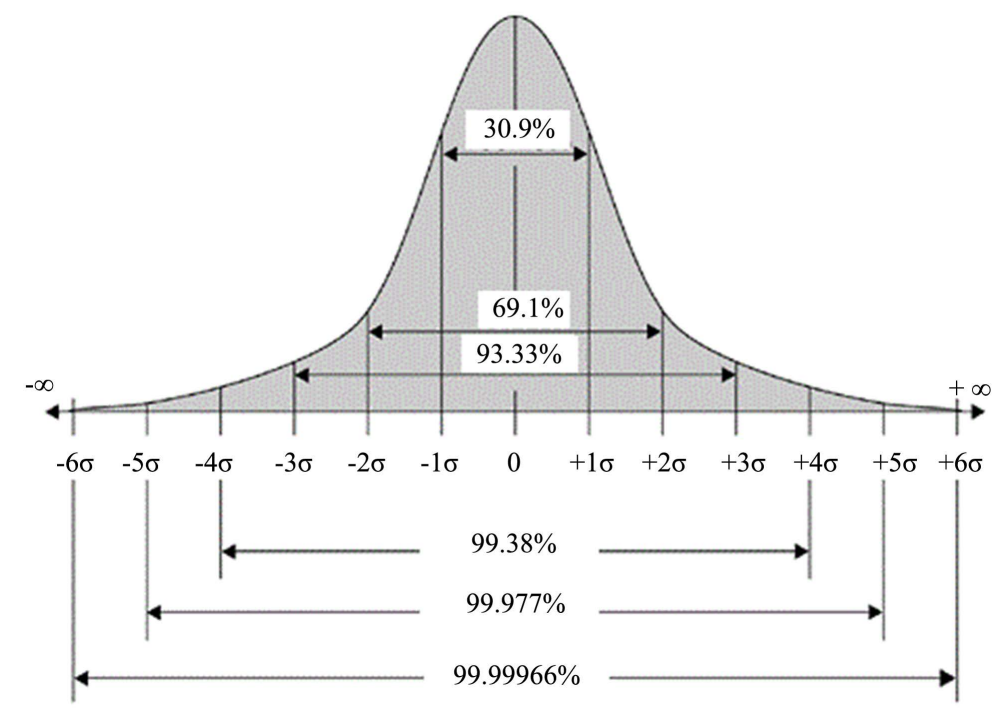

Figure 1. Six sigma $(6 \sigma)$ and normal distribution.

Table 1. Sigma performance levels.

\begin{tabular}{cccc}
\hline Sigma Level $(\sigma)$ & DPMO & Defects (\%) & Yield (\%) \\
\hline 6 & 3.4 & 0.00034 & 99.99966 \\
5 & 233 & 0.023 & 99.977 \\
4 & 6.210 & 0.62 & 99.38 \\
3 & 66.807 & 6.68 & 93.33 \\
2 & 308.537 & 30.8 & 69.2 \\
\hline
\end{tabular}

\section{Six Sigma's DMAIC}

\subsection{Define Phase}

The primary objective of Six Sigma is to reduce variations, in products and processes, to achieve high quality levels. To identify weaknesses and eliminate defects in the process, Six Sigma makes use of a structured sequence of steps called DMAIC (Define, Measure, Analyze, Improve and Control) and finds the root causes behind problems to reach near perfect processes.

In each hospital under study, a Six Sigma team was gathered from a surgeon, nurse and technician. As the desired outcomes, the teams first defined the objectives of their surgical processes (Table 2).

The team defined a "complication" as a defect, i.e. any unwanted outcome inhibiting the patient to be cured and stable which compounds the illness and decreases the patient's quality of life or prolongs the planned hospital stay [13]. They noted the complications as they occurred. They stated that the surgical process with less amount of complications has higher success [16]. Thus, they used DMAIC to analyse, improve and modify the complicated ophthalmic processes by identifying and eliminating root causes of the complications.

Table 2 records the results of a range of eye surgeries, their length of duration and their success rates measured on the sigma level. While the duration of surgeries varies between surgery types, it may also be different within the same surgery type depending on the amount of time it takes to achieve the objective.

\subsection{Measure Phase}

The team calculated the sigma level of each complication and type of surgery from DPMO (Table 2). DPMO is calculated from Equation (1) as follows [13]: 
Table 2. Number, duration, yield, sigma level and objective per surgery type.

\begin{tabular}{|c|c|c|c|c|c|c|}
\hline Surgery & Surgery Name & Objective & $\begin{array}{l}\text { Number of } \\
\text { Surgeries }\end{array}$ & $\begin{array}{c}\text { Duration } \\
\text { (mins) }\end{array}$ & $\begin{array}{l}\text { Yield } \\
(\%)\end{array}$ & $\begin{array}{l}\text { Sigma } \\
\text { Level }\end{array}$ \\
\hline I & LASIK Surgery & Emmetropia; Corrected Refractive Error & 2357 & $5-10$ & 98.7 & 3.7135 \\
\hline II & Strabismus Surgery & $\begin{array}{l}\text { Orthophoria; Binocular Function; Ocular } \\
\text { Alignment; High Visual Acuity; Fusion }\end{array}$ & 473 & $30-60$ & 95.6 & 3.2025 \\
\hline III & Intravitreal Injection & $\begin{array}{l}\text { Improvement of Vision Acuity; } \\
\text { Prevention of Worsening of Visual Acuity }\end{array}$ & 229 & $2-3$ & 96.1 & 3.2657 \\
\hline IV & $\begin{array}{l}\text { Phacoemulsification } \\
\text { Cataract Surgery }\end{array}$ & High Visual Acuity & 1050 & $10-30$ & 99.4 & 3.9580 \\
\hline $\mathrm{V}$ & $\begin{array}{l}\text { Cataract Surgery in Patients } \\
\text { with Pseudoexfoliation Syndrome }\end{array}$ & High Visual Acuity & 151 & $20-30$ & 98.6 & 3.7030 \\
\hline VI & Pars plana vitrectomy & High Visual Acuity; High Vision Quality & 2272 & $60-120$ & 99.1 & 3.8559 \\
\hline VII & IntraLase Surgery & Emmetropia; Corrected Refractive Error & 448 & $5-10$ & 96.9 & 3.3547 \\
\hline VIII & Penetrating keratoplasty & $\begin{array}{l}\text { Improved Visual Acuity; Excellent } \\
\text { Prognosis; Clear Cornea }\end{array}$ & 59 & $60-90$ & 95.0 & 3.1418 \\
\hline IX & Trabeculectomy & $\begin{array}{l}\text { IOP under control; Long-term Survival of } \\
\text { Optic Nerve; Preservation of Visual } \\
\text { Acuity; Preservation of Visual Field }\end{array}$ & 253 & $25-35$ & 94.9 & 3.1391 \\
\hline
\end{tabular}

$$
\mathrm{DPMO}=1,000,000 \times(B / A)
$$

where $A$ is the total number of surgeries performed and $B$ is the total number of complications occurred. Then, DPMO is translated to a Sigma level of Z-statistic. For a given sigma level, the DPMO is provided, assuming normality and a 1.5 sigma shift [16]. The higher level of sigma indicates a lower rate of complications and a more efficient process [16].

A total of 7292 procedures have already been carried out. Among the nine types of surgeries, phacoemulsification cataract surgeryyielded the highest sigma level (3.9580), whereas trabulectomy did the lowest (3.1391).

Alternate methods (e.g. Lasik surgery vs Intralase surgery; phacoemulsification cataract surgery vs cataract surgery in patients with pseudoexfoliation syndrome) demonstrate that lasik surgery (3.7135) and phacoemulsification cataract surgery (3.9580) result in having more successful surgerical processes than IntraLase surgery (3.3547) and cataract surgery in patients with pseudoexfoliation syndrome (3.7030), respectively.

Sigma levels for all surgery types were found to be under 4.00 sigma level indicating that all processes need improvement and preventative/corrective actions. From the sigma levels per surgery type in Table 2, the average is measured and found that the eye surgery processes in Turkey operates at a 3.4816 sigma level. If it were assumed that each surgery yielded at most one complication, this level would correspond to a DPMO of 23,725 and a yield of approximately $97.63 \%$ in 7292 surgeries. This means that the Turkish eye care hospitals have to make significant changes to drive to a $6 \sigma$ level performance.

Then, the team prioritized the complications according to how serious their consequences were (i.e. severity score) and how frequently they occurred (i.e. occurrence rate). They determined the severity of each complication and assigned scores for them. The severity of each complication was scored from 1 to 4 (i.e. a complication with no harm = 1 ; temporary harm = 2; permanent harm = 3; death $=4$ ).

Severity score for all the observed complications per surgery type are listed in Table 3 along with their occurence rates (\%) and sigma levels.

\subsection{Analyze Phase}

The teams evaluated each process while attempting to assess the multipleCritical-to-Quality (CTQ) factors that cause each acute, sub-acute and chronicpre-, intra- and post-surgical complication (Table 4). By brainstorming, the team identified the quality factors affecting each process. They determined that the complications were caused by the surgeon, assistant surgeon, nurse, technician, anaesthesiologist, patient, donor cornea, equipment, materials and hygiene. Then, they analyzed the processes depending on the effect frequency of each quality factor. Then, they separated these factors according to how frequently they affect the process and cause a 
Table 3. Severity score of complications (Occurrence Rate \%; Sigma Level) per Surgery Type.

\begin{tabular}{|c|c|c|c|c|}
\hline & \multicolumn{4}{|c|}{ Severity Score } \\
\hline & 1 & 2 & 3 & 4 \\
\hline LASIK & $\begin{array}{l}\text { Subconjunctival } \\
\text { haemorrhage } \\
\text { (55.49\%; 1.36), } \\
\text { Interface debris } \\
\text { (0.17\%; 4.43). }\end{array}$ & $\begin{array}{c}\text { Dry eye syndrome } \\
\text { (100\%; -6.26), } \\
\text { Limbal Haemorrhage } \\
\text { (0.81\%; 3.91), } \\
\text { Epithelial erosion } \\
\text { (0.25\%; 4.30), } \\
\text { Decentered flap } \\
\text { (0.25\%; 4.30), } \\
\text { Free flap } \\
(0.04 \% ; 4.84) .\end{array}$ & $\begin{array}{c}\text { Epilethial ingrowth } \\
(0.47 \% ; 4.10) \text {, Thin flap } \\
(0.47 \% ; 4.10) \text {, } \\
\text { Undercorrection } \\
(0.47 \% ; 4.10) \text {, } \\
\text { Overcorrection } \\
\text { (0.30\%; 4.25), Shifting sands } \\
\text { of the Sahara (0.08\%; 4.64), } \\
\text { Wrinkles }(0.08 \% ; 4.64) \text {, } \\
\text { Small flap }(0.04 \% ; 4.84) .\end{array}$ & $\begin{array}{c}\text { Flap edge melt (2.84\%; 3.40), } \\
\text { Incomplete flapv } \\
(0.21 \% ; 4.36), \\
\text { Buttonhole }(0.08 \% ; 4.64), \\
\text { Wrong insertion of } \\
\text { patient’s biometric data } \\
(0.08 \% \text {; 4.64), Inadequate suction } \\
(0.04 \% ; 4.84), \\
\text { Sliding flap }(0.04 \% ; 4.84) .\end{array}$ \\
\hline Strabismus & $\begin{array}{c}\text { Haemorrhage } \\
\text { (100\%; -6.35), } \\
\text { Neusea and vomiting } \\
\text { (28.96\%; } 2.05) \text {, Corneal } \\
\text { abrasions (0.63\%; 3.99). }\end{array}$ & $\begin{array}{c}\text { Bleeding } \\
\text { (1.48\%; 3.68), } \\
\text { Prolapsed } \\
\text { Tenon’s capsule } \\
\text { (0.21\%; } 4.36) .\end{array}$ & $\begin{array}{l}\text { Partial scleral damage } \\
\text { (0.85\%; 3.89), } \\
\text { Surgery to the } \\
\text { wrong muscle } \\
(0.63 \% ; 3.99) .\end{array}$ & 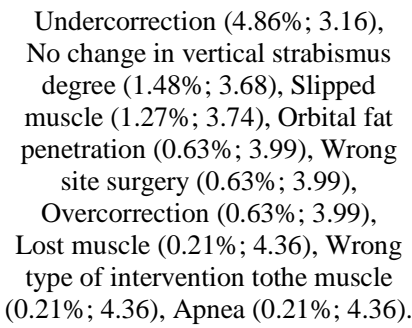 \\
\hline $\begin{array}{c}\text { Intravitreal } \\
\text { Injection }\end{array}$ & $\begin{array}{l}\text { Subconjunctival } \\
\text { Haemorrhage } \\
\text { (45.85\%; 1.60). }\end{array}$ & $\begin{array}{c}\text { Increase in IOP } \\
\text { (18.34\%, 2.40), } \\
\text { Anterior uveitis } \\
\text { (6.99\%; 2.98), } \\
\text { Anterior/Posterior } \\
\text { Inflammation } \\
\text { (2.18;3.52). }\end{array}$ & Cataract (0.44\%; 4.12) & $\begin{array}{c}\text { Endophthalmitis } \\
\text { (0.44\%; 4.12), } \\
\text { Retinal detachment } \\
(0.44 \% ; 4.12) .\end{array}$ \\
\hline Phacoemulsification & $\begin{array}{c}\text { Capsular tension ring } \\
\text { Implantation } \\
(0.57 \% ; 4.03) \text {, } \\
\text { Retained cortex } \\
\text { material (0.76\%; 3.93), } \\
\text { Iridodonesis } \\
(1.44 \% ; 3.78) .\end{array}$ & $\begin{array}{c}\text { Damage to the IOL } \\
\text { (1.33\%; 3.72), Iris } \\
\text { prolapse (0.19\%; } 4.39) \text {, } \\
\text { Pupillary irregularity, } \\
\text { Iris atrophy } \\
\text { (2.86\%; 3.40), Fibrin } \\
\text { reaction }(0.76 \% ; 3.93) \text {. }\end{array}$ & $\begin{array}{c}\text { Radial tears in the anterior } \\
\text { capsule }(0.57 \% ; 4.03) \text {, } \\
\text { Iridodialysis }(0.095 \% ; 4.60) \text {, } \\
\text { Zonular disinsertion } \\
(0.095 \% ; 4.60) \text {, } \\
\text { Intraocular pressureelevation } \\
\text { and Glaucoma }(1.91 \% ; 3.20) \text {, } \\
\text { Irvine-Gass syndrome } \\
(1.52 \% ; 3.66) .\end{array}$ & $\begin{array}{c}\text { Posterior capsular tear } \\
(2.09 \% ; 3.53), \\
\text { Endophthalmitis } \\
(0.38 \% ; 4.17) \text {, } \\
\text { Corneal edema and } \\
\text { bullous keratopathy } \\
(0.095 \% ; 4.60) .\end{array}$ \\
\hline Pseudoexfoliation & $\begin{array}{c}\text { Iris retraction hooks } \\
\text { (2.64\%; 3.44), } \\
\text { Retained cortex } \\
\text { material }(0.66 \% ; 3.98) \text {, } \\
\text { Pupillar membrane } \\
(0.66 \% ; 3.98)\end{array}$ & $\begin{array}{c}\text { Glaucoma (1.98\%; 3.56), } \\
\text { Pupillary irregularity } \\
\text { (0.66\%; 3.98), } \\
\text { Iris sphincter tears } \\
\text { (0.66\%; 3.98). }\end{array}$ & $\begin{array}{c}\text { Zonular dialysis } \\
\text { (2.64\%; 3.44), } \\
\text { Iridodialysis (0.66\%; 3.98). }\end{array}$ & $\begin{array}{l}\text { Posterior capsule rupture } \\
\text { (11.25\%; 2.71), } \\
\text { IOL disclocation } \\
(0.66 \% ; 3.98) .\end{array}$ \\
\hline $\begin{array}{l}\text { Pars plana } \\
\text { vitrectomy }\end{array}$ & $\begin{array}{c}\text { Posterior synechiae } \\
\text { (5.24\%; 3.12), } \\
\text { Conjunctival } \\
\text { haemorrhage } \\
\text { (30.24\%; 2.02). }\end{array}$ & $\begin{array}{c}\text { Cystoid macular edema } \\
\text { (2.82\%; 3.41), Glaucoma } \\
\text { (1.94\%; 3.57), Hypertony } \\
\text { (1.67\%; 3.63), Iatrogenic } \\
\text { retinal hemorrhage } \\
\text { (0.75\%; 3.93), Hypotony } \\
\text { (0.66\%; 3.98), Silicone oil } \\
\text { into anterior Chamber } \\
\text { (0.53\%; 4.06), Migration of } \\
\text { gas into anterior chamber } \\
\text { (0.48\%; } 4.09), \text { IOL } \\
\text { dislocation (0.31\%; } 4.24) \text {, } \\
\text { Complete dislocation } \\
\text { of the IOLinto the } \\
\text { vitreous cavity } \\
\text { (0.18\%; } 4.42), \text { Posterior } \\
\text { capsular tear (0.18\%; 4.42), } \\
\text { Endophthalmitis } \\
\text { (0.18\%; 4.42), } \\
\text { Expulsive haemorrhage } \\
\text { (0.08\%; 4.63). }\end{array}$ & 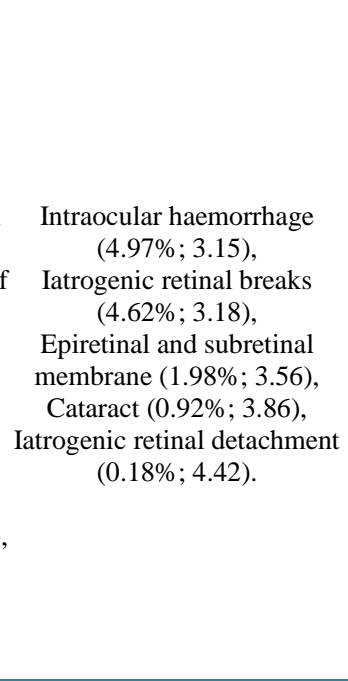 & $\begin{array}{c}\text { Retinal redetachment } \\
\text { (3.04\%; 3.38), } \\
\text { Choroidal detachment } \\
(0.04 \% ; 4.83), \\
\text { Escape of gas } \\
(0.13 \% ; 4.51) .\end{array}$ \\
\hline
\end{tabular}




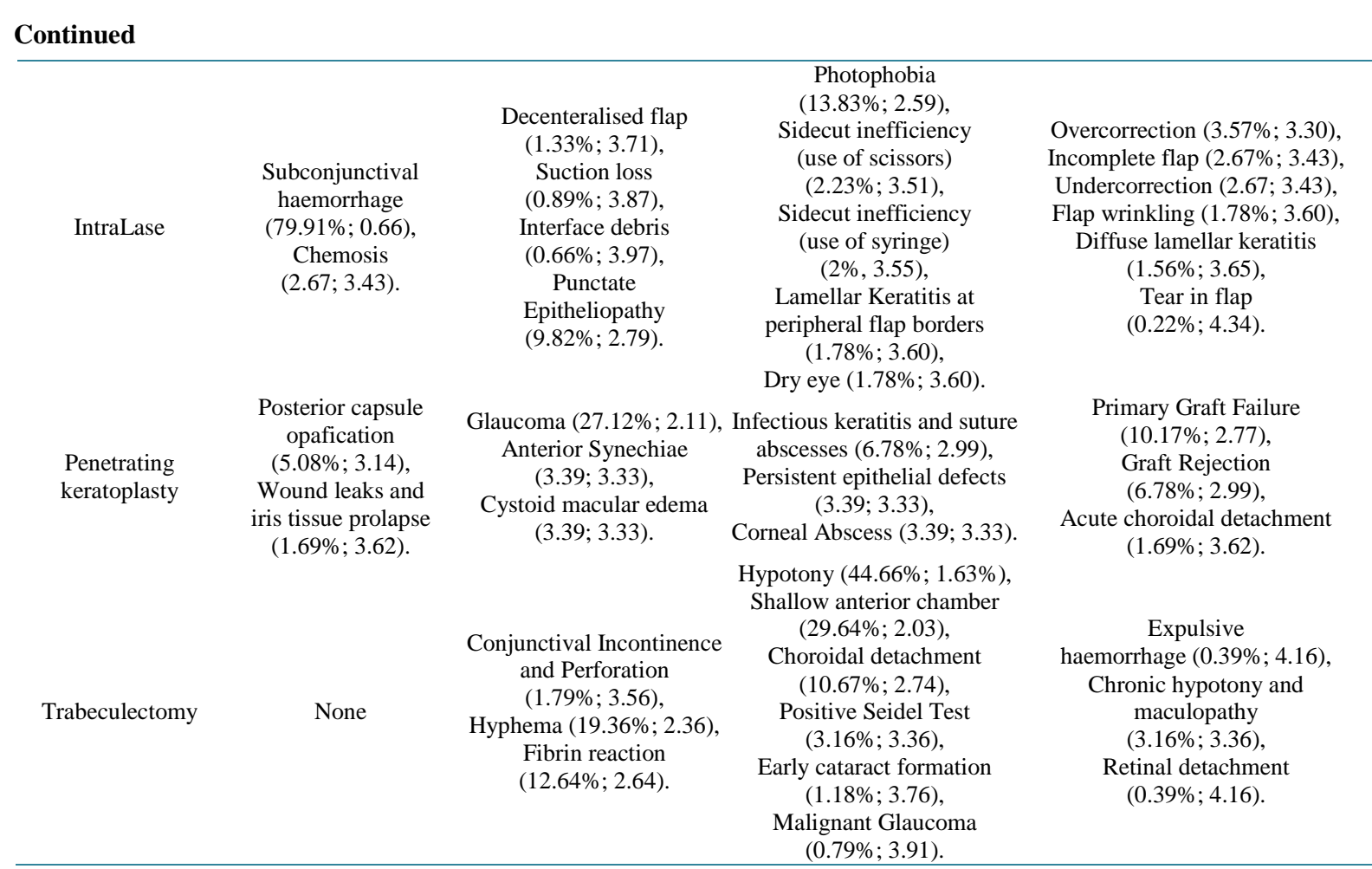

complication: "Vital few" CTQs are those factors that affect the process the most and are often the main sources of the complications (Table 4).

\subsection{Improve Phase}

The Six Sigma team recommended the following improvements in the eye units:

The demand of everyday life places an ever increasing burden not only on the active surgeon but also on all members of his inherent team. The team must be trained on Six Sigma; understand Six Sigma philosophies and principles, including the supporting systems and tools and understands all aspects of the DMAIC model in accordance with Six Sigma principles.

The burden and pace of ophthalmic techniques places an obligation on both the surgeon and his team to make every effort to adapt, whenever possible, to ensure that all modern techniques are well known, practised and when required revised and improved by his team through constant consultation and feedback.

Being the black belt who leads problem-solving projects, the surgeon has to demonstrate team leadership. The focus of all success in this ophthalmic endeavour falls on the shoulders of well-qualified, updated, experienced and efficient surgeon. A surgeon needs to be knowledgeable, experienced, procedurally skilled and have good judgment. These include the knowledge of the tools, instruments and materials used, anaesthesia, the knowledge to treat injury and understanding of the techniques and indications of the types of surgical procedures. The absence of any of the above qualities will impair his surgical procedure.

Any ophthalmic surgery demands qualifications that are obtained by special training and skills. However, no matter how carefully planned and supervised a training program, some complications cannot be prevented. Thus, a required part of surgical training must be experience with complications and unexpected events. These criteria are self evident to a proficient surgeon. Without required knowledge and experience, they will be unable to cope with such situations as will arise. Thus, an essential component of a fully developed surgeon comes from diligent experience in situations where complications and unexpected events arise.

The surgeon must maintain a highly flexible approach to learning as many of the details even though some of the principles may change with time. Refinements and improvements develop at such a remarkable rate that every surgeon must realize that techniques widely used today may be outdated in the very near future. In fact, this flexible approach to learning is a requirement for reducing the number and type of complications and thus, 
Table 4. CTQs per surgery type.

\begin{tabular}{|c|c|c|}
\hline Surgery & Vital Few CTQ & Trivial Many CTQ \\
\hline I & $\begin{array}{l}\text { Experience of refractive surgeon; Type of } \\
\text { microkeratome; Hygiene of microkeratome }\end{array}$ & $\begin{array}{l}\text { Cleaning of Patient's Cornea by Refractive Surgeon; } \\
\text { Patient's Eye Anatomy }\end{array}$ \\
\hline II & $\begin{array}{l}\text { Patient's eye anatomy; experience of anaesthesiologist; } \\
\text { experience and attention of strabismus surgeon }\end{array}$ & $\begin{array}{c}\text { Type and Quality of Suture; Attention of assistant } \\
\text { surgeon; Attention of nurse }\end{array}$ \\
\hline III & $\begin{array}{l}\text { Experience of retina specialist; Attention of retina } \\
\text { specialist; Patient's ocular pathology }\end{array}$ & $\begin{array}{l}\text { Sterilization and hygiene; Dosage of drug/agent; } \\
\text { Chemical properties of drug/agent }\end{array}$ \\
\hline IV & $\begin{array}{l}\text { Experience of ophthalmic surgeon; Patient's } \\
\text { anatomy; Cooperation of patient during surgery }\end{array}$ & $\begin{array}{c}\text { Sterilization and hygiene; Attention of assistant surgeon; } \\
\text { Calibration of equipment; Quality/chemical } \\
\text { composition of intraocular material }\end{array}$ \\
\hline $\mathrm{V}$ & $\begin{array}{l}\text { Experience of ophthalmic surgeon; Patient’s } \\
\text { anatomy; Cooperation of patient during surgery }\end{array}$ & $\begin{array}{c}\text { Sterilization and hygiene; Attention of assistant surgeon; } \\
\text { Calibration of equipment; Quality/chemical } \\
\text { composition of intraocular material }\end{array}$ \\
\hline VI & $\begin{array}{l}\text { Experience of vitreoretinal surgeon; Attention of } \\
\text { vitreoretinal surgeon; Patient's anatomy }\end{array}$ & $\begin{array}{c}\text { Sterilization and hygiene; Amount of silicone oil; } \\
\text { Amount of gas }\end{array}$ \\
\hline VII & $\begin{array}{c}\text { Experience of refractive surgeon; Patient's anatomy; } \\
\text { Calibration of laser power }\end{array}$ & $\begin{array}{c}\text { Patient's psychology; Sterilization and hygiene; } \\
\text { Suction-ring's pressure }\end{array}$ \\
\hline VIII & Patient’s eye anatomy; Suitability of donor cornea & $\begin{array}{l}\text { Experience of ophthalmic surgeon; Sterilization } \\
\text { and hygiene; Performance of equipment }\end{array}$ \\
\hline IX & Patient's eye anatomy; Experience of ophthalmic surgeon & $\begin{array}{c}\text { Quality of surgical equipment; Quality and type } \\
\text { of suture; Experience of staff }\end{array}$ \\
\hline
\end{tabular}

improving the overall surgical process.

The surgeon should be well-prepared for the surgery. This requires knowledge of the desired goals, the patient, the materials used, the techniques employed and oneself. In addition, the surgeon must be in control of the whole procedure, including what happens prior to the actual surgical procedure, what happens in the operating room, including the surgical team and the appropriate surgical technique.

Even before the surgery starts, the qualifications of separate individuals and how well they function together as a team is paramount to the success of the procedure about to be undertaken. No individual is too important or unimportant simply because the procedure does not flow freely. However, each surgical procedure, while independent, still depends on the separate efficiencies of the individuals involved.

Because a successful team functions throughout surgery as a medical entity, each member is in effect a subset of a larger unit. As each team is comprised of the sum of its parts, the burden of success is shared by each team member to the degree that the other members of the team rely on them. No individual can be considered as too important or unimportant, high and low of the attempt of the impending surgery is to be a success.

Recent technological developments has dramatically changed surgeon's roles by providing the means for surgeons to be more effective [17]. What is more, very convincing improvements in the surgical instruments and materials have resulted due to these open-ended advances. However, the techniques used are being adopted so rapidly and extensively that a single surgeon cannot possibly be fully competent in all aspects.

The surgeon's success will depend in no small part on the quality and type of the range of materials (e.g. suture, intraocular material) he has at hand. He is required to be fully satisfied and perform regular checks on the materials he uses as they will no longer be visible on completion of surgery. Examples of these are a comprehensive knowledge of the range of intraocular material, their restricted usage and their mean life time. A surgeon's updated knowledge and comprehension of the best dosage and frequency of e.g. drugs, agents, silicone oil, gas, is always required dealing with the age, condition and seriousness of the condition being treated.

In the midst of the surgical procedure, a surgeon must not divert his attention. The sole purpose of his work is efficiency in achieving as best he possibly can a successful outcome to the patient he is presently attending. To achieve this success, a proficient and professional atmosphere must be maintained (e.g. no external distraction, no annoyances within the workplace, no potential disturbances from outside during functional hours) where everybody knows the sequence, the dangers and the precautions which are required on completion of the surgery. 
A clear indicator of a surgeon's efficiency and care for his patient will be decided by the quality of the instrumentation he uses everyday in his surgery. While the best equipment may not always guaranteee the perfect result, it is a statement by the surgeon that he approaches all surgery in the most professional manner.

Ensuring good visualization of the surgical field is an essential principle. Seeing clearly requires proper direction and intensity of lighting, proper positioning of the patient, skillful assistants, proper positioning of the surgeon's hands and competence in the use of approporiate optical aids.

Every professional category learns best from within its own circle. For this reason, assistant surgeons require exposure frequently on the present and new techniques being practised within the operating room. It can also be of great value to have readily written reference available in the operating room so that junior team members have access to them at all functional times.

For people who encounter ocular health problems resulting in e.g. poorer vision; the treatment and quality of eye surgery available is of special importance. Ophthalmic patients often require excellent medical, surgical and emotional care. However, complete success is not an invariable outcome of surgical treatment. Thus, patients must be prepared to accept results desirable than hoped for. Each patient is unique with his or her nature, needs and wants. Thus, surgeons must understand the unique qualities of each patient at each interaction and patient's response to disease. It is also vital that the patient must have confidence in his or her surgeon, and that the confidence is deserved.

Nurses are trained to become the green belts of Six Sigma projects. They must assist the black belt surgeon with data collection; analyzing and solving quality problems. Assistant surgeons are the yellow belts as theyhave a small role, interest, or need to develop foundational knowledge of Six Sigma, whether as an entry level employee..

Nurses must make sure that noone in the staff breaks the hygiene rules since the success of any medical procedure must begin with strict adherence to hygenic standards. In addition, those higher up in contact with a patient throughout surgery bear a heavy burden to ensure success as maintaining hygenic standards and practices. Infections are a major cause of preventable ocular morbidity. The surgeon and his team should be alert to the possibility that ophthalmic instruments are improperly sterilized and contaminated ophthalmic solutions are infected. Hands also play a major role in the transmission of infection. They should be washed or disinfected before and after the examination of every patient.

The advent of improved products such as lenses requires the surgeon to pay close and consistent reference to the new products available so as to ensure the ocular health of his patients. Constant reference to catalogue results will help him to choose the proper item or range of items.

Prior to undergoing any surgical procedure, a detailed examination of the overall health and specific ailment of the patient must be prepared by the most proficient professional. Any additional conditions (e.g. diabetes) must be clearly brought to the teams' attentions and in the weeks before surgery occurs. The same condition should be checked by both the local doctor and the patient.

Throughout surgery, the patient will respond to its alien surrounding if he has clearly been informed of the stages required in the simplest possible language and if required, this knowledge can be repeated in a friendly manner. A clear contrast exists here between a team who are functioning together daily and a patient who is experiencing this procedure for the first time in foreign surroundings. The success of the patient is more important than the success of the procedure although the patient's health has without doubt dependent on the procedure just carried.

As soon as a patient leaves surgery, he is at his vulnerable requiring regular and friendly checkups to ensure the patient is getting better. Contact with members of family can help to ensure the patient is relaxed after surgery and also gives the surgeon an occasion to mention any potential complications which may result from the procedure just finished.

Subsequent examination of the patient's recovery visits must be carried out by the best qualified individual appointed by the surgeon with steady contact being available to surgeon to report and record any potential complications.

Follow-up examinations by the surgeon or his team also require a realistic assessment of the patients' post-operational recouperation with any complications being dealt with as quickly and efficiently as possible. A few words of encouragement by the medical team to describe the procedure carried out on the patient as having been successful will go a long way to remove the natural worries a patient will always have. The patient needs to know how best he can part take in his own recovery. Such aids as eye drops and regular eye washing with a 
reputed eye lotion and informing the surgeon of any potential infection will be necessary.

\subsection{Control Phase}

To keep the surgical processes under control, the team initiated and implemented the improvement plan. Although it was subject to revision with a view of standardising the tested improved surgical processes, knowledge gained from corrective/preventative recommendations was shared and institutionalised.

\section{Conclusions}

This study has shown potential use of Sigma Quality Level as a statistical index that provides a quantitative measure of the capability of specialised eye care processes. Sigma level can both be used as an organizational or industrial metric in healthcare.

A sigma level is a measure of the error rate of a process, based on the DPMO estimate. It offers an indicator of how often complications are likely to occur, where a higher sigma level indicates a process that is less likely to create complications. Consequently, as sigma level of quality increases, reliability of the surgery improves, the need for reoperation diminishes, follow-up time declines, surgery duration length goes down, costs go down, and patient satisfaction goes up. In addition, sigma level can be used to measure the occurence of a complication or the success rate of a surgery. A surgery that yields a low number of complications will have a high sigma level.

By determining the sigma level, practitioners can make use of Six Sigma's DMAIC to prevent the occurrence of complications. First, CTQs should be determined. Then, preventative measures should be undertaken for each complication. This will remove variation from ophthalmic processes and fewer complications inherently result. A reduction in complications can, in turn, help eliminate waste from processes in the following ways: fewer complications decrease the number of materials that must be scrapped; and fewer complications also mean that energy, costs (e.g. insurance cost, re-operation cost, psychological burden, cost of labour, materials cost, training cost) and time to follow-up and re-work the patient to fix the complications are eliminated.

To achieve such continuous improvement by Six Sigma, leadership commitment is necessary. Eye care center's top management (and surgeon as a black belt in Six Sigma projects) is in a position to initiate Six Sigma deployment and play an active role in the whole deployment cycle. Six Sigma starts by providing senior leadership with training in the Six Sigma principles and tools, and it needs to direct the development of a management infrastructure to support it. This involves reducing the organizational hierarchy levels and removing procedural barriers to change.

The return on investment gained from the information and knowledge the DMAIC tool creates can be substantial. This tool requires a great deal of coordination within the team. If achieved, it can greatly improve a eye care processes' ability to be controlled and analyzed during process improvement projects.

Throughout this study, attention has been given to the best available information at hand and is presented in a factual manner, to be of use to the greatest possible range of medical personnel.

The proposed method is versatile enough to incorporate any further clinical developments which take place into the future. The medical world plays no small part in the updating of their operational results so that all involved can have a realistic scale of medical procedures. A databank, reviewing and updating sigma levels, needs to be established and directed through a range of medical practitioners with thte most updated qualifications in their varied range of eye surgeries.

A variety of different headings would be required to ensure that this method will have the success rate in highlighting and correcting any complications which result from the surgery technique used.

The Six Sigma methodology has proved both informative and versatile in addressing the core facts and it is our belief that it can easily been adapted to suit a range of studies in other related or distinct fields of medicinedentistry, anaesthesia and orthopedics to name a few.

\section{References}

[1] Probst, L.E., Tsai, J.H. and Goodman, G. (2012) Ophthalmology: Clinical and Surgical Principles. Slack Incorporated, Thorofare, NJ.

[2] Boyd, S. and Wu, L. (2009) Management of Complications in Ophthalmic Surgery. Jaypee Highlights Medical Publishers Inc., Panama. 
[3] Agarwal, A. and Jacob, S. (2012) Complications in Ocular Surgery: A Guide to Managing the Most Common Challenges. Slack Incorporated, Thorofare, NJ.

[4] Oztürker, C., Sahbaz, I., Oztürker, Z.K., Taner, M.T., Bayraktar, S. and Kagan, G. (2014) Development of a Six Sigma Infastructure for Trabulectomy Process. American Journal of Operations Research, 4, 246-254. http://dx.doi.org/10.4236/ajor.2014.44024

[5] Sahbaz, I., Taner, M.T., Sahandar, U.T., Kagan, G. and Erbas, E. (2014) Elimination of Post-Operative Complications in Penetrating Keratoplasty by Deploying Six Sigma. American Journal of Operations Research, 4, 189-196. http://dx.doi.org/10.4236/ajor.2014.44018

[6] Sahbaz, I., Taner, M.T., Eliacik, M., Kagan, G. and Erbas, E. (2014) Adoption of Six Sigma’s DMAIC to Reduce Complications in IntraLase Surgeries. International Journal of Statistics in Medical Research, 3, 126-133. http://dx.doi.org/10.6000/1929-6029.2014.03.02.6

[7] Sahbaz, I., Taner, M.T., Eliacik, M., Kagan, G., Erbas, E. and Enginyurt, H. (2014) Deployment of Six Sigma Methodology to Reduce Complications in Intravitreal Injections. International Review of Management and Marketing, 4, 160-166.

[8] Sahbaz, I., Taner, M.T., Kagan, G., Sanisoglu, H., Durmus, E., Tunca, M., Erbas, E., Kagan, S.B., Kagan, M.K. and Enginyurt, H. (2014) Development of a Six Sigma Infrastructure for Cataract Surgery in Patients with Pseudoexfoliation Syndrome. Archives of Business Research, 2, 15-23. http://dx.doi.org/10.14738/abr.22.173

[9] Sahbaz, I., Taner, M.T., Kagan, G., Sanisoglu, H., Erbas, E., Durmus, E., Tunca, M. and Enginyurt, H. (2014) Deployment of Six Sigma Methodology in Phacoemulsification Cataract Surgeries. International Review of Management and Marketing, 4, 123-131.

[10] Sahbaz, I., Taner, M.T., Sanisoglu, H., Kar, T., Kagan, G., Durmus, E., Tunca, M., Erbas, E., Armagan, I. and Kagan, M.K. (2014) Deployment of Six Sigma Methodology to Pars Plana Vitrectomy. International Journal of Statistics in Medical Research, 3, 94-102. http://dx.doi.org/10.6000/1929-6029.2014.03.02.3

[11] Taner, M.T., Kagan, G., Sahbaz, I., Erbas, E. and Kagan, S.B. (2014) A Preliminary Study for Six Sigma Implementation in Laser in Situ Keratomileusis (LASIK) Surgeries. International Review of Management and Marketing, 4, $24-$ 33.

[12] Taner, M.T., Sahbaz, I., Kagan, G., Atwat, K. and Erbas, E. (2014) Development of Six Sigma Infrastructure for Strabismus Surgeries. International Review of Management and Marketing, 4, 49-58.

[13] Taner, M.T., Kagan, G., Celik, S., Erbas, E. and Kagan, M.K. (2013) Formation of Six Sigma Infrastructure for the Coronary Stenting Process. International Review of Management and Marketing, 3, 232-242.

[14] Taner, M.T., Sezen, B. and Antony, J. (2007) An Overview of Six Sigma Applications in Healthcare Industry. International Journal of Health Care Quality Assurance, 20, 329-340. http://dx.doi.org/10.1108/09526860710754398

[15] Conlin, M. (1998) Revealed at Last: The Secret of Jack Welch’s Success. Forbes, 16, 44.

[16] Taner, M.T. (2013) Application of Six Sigma Methodology to a Cataract Surgery Unit. International Journal of Health Care Quality Assurance, 26, 768-785. http://dx.doi.org/10.1108/IJHCQA-02-2012-0022

[17] Spath, G.L., Danesh-Meyer, H., Goldberg, I. and Kampik, A. (2012) Ophthalmic Surgery: Principles and Practice. 4th Edition, Elsevier Health Sciences, Edinburgh. 